\title{
Effects of Astragalus membranaceus roots supplementation on growth performance, serum antioxidant and immune response in finishing lambs
}

\author{
Xiaoyan Hao ${ }^{1, a}$, Pengju Wang ${ }^{1, a}$, Youshe Ren ${ }^{1,2}$, Gentang Liü, Jianxin Zhang ${ }^{1,2}$, \\ Brian Leury ${ }^{4}$, and Chunxiang Zhang ${ }^{1,2, *}$
}

\footnotetext{
* Corresponding Author: Chunxiang Zhang Tel: +86-354-6285990, Fax: +86-354-6288052, E-mail: zhchx66@126.com

${ }^{1}$ College of Animal Science and Veterinary, Shanxi Agricultural University, Taigu 030801, China

2 Shanxi Collaborative Innovation Center for HighProductive and Safe Livestock, Taigu 030801, China ${ }^{3}$ Institution of Husbandry and Veterinary, Yingxian 037600, China

${ }^{4}$ Faculty of Veterinary and Agricultural Sciences,

University of Melbourne, Victoria 3010, Australia

${ }^{a}$ Xiaoyan Hao and Pengju Wang contributed equally to this article.

\section{ORCID}

Xiaoyan $\mathrm{HaO}$

https://orcid.org/0000-0002-2710-0744 Pengju Wang

https://orcid.org/0000-0001-5057-7287

Youshe Ren

https://orcid.org/0000-0002-0984-6198

Gentang Liu

https://orcid.org/0000-0002-2699-8708 Jianxin Zhang

https://orcid.org/0000-0001-8165-1371

Brian Leury

https://orcid.org/0000-0001-9173-2730

Chunxiang Zhang

https://orcid.org/0000-0002-4973-2363
}

Submitted Apr 10, 2019; Revised Jun 10, 2019: Accepted Jul 29, 2019
Objective: Astragalus membranaceus root is a well-known traditional Chinese herbal medicine with many biological active constituents. This study was conducted to examine the effects of Astragalus membranaceus root powder (AMP) on growth performance, serum antioxidant and immune response in finishing lambs.

Methods: A total of thirty-six Guangling fat-tailed ram lambs (body weight $=19 \pm 2 \mathrm{~kg}$, mean \pm standard deviation) were randomly assigned to one of six treatments for a $40 \mathrm{~d}$ feeding period, with the first $10 \mathrm{~d}$ for adaptation. Treatments consisted of the lambs' basal diets with addition of $0,5,10,15,20$, and $30 \mathrm{~g} / \mathrm{kg}$ of diet of AMP.

Results: Response to supplementation level of AMP was quadratic $(\mathrm{p} \leq 0.032)$ for final weight and ADG with the greatest at $10 \mathrm{~g} / \mathrm{kg}$ of diet, but dry matter intake was not affected ( $\mathrm{p} \geq$ 0.227 ) by treatments. The increase of AMP supplementation resulted in a quadratic response in contents of triglyceride and creatinine $(\mathrm{p}<0.05)$, with the lowest values for 10 and $20 \mathrm{~g} / \mathrm{kg}$ of diet, respectively. A linear and quadratic decrease was observed in activity of alkaline phosphatase in serum of lambs. As the AMP supplementation increased, the activities of total superoxide dismutase and total antioxidant capacity increased linearly $(\mathrm{p} \leq 0.018)$ and hydroxyl radical $\left(\mathrm{OH}^{-}\right)$decreased linearly $(\mathrm{p}=0.002)$. For catalase $(\mathrm{CAT})$ and malondialdehyde $(\mathrm{MDA})$, quadratic $(\mathrm{p} \leq 0.001)$ effects were observed among treatments, with the greatest CAT and lowest MDA values at $10 \mathrm{~g} / \mathrm{kg}$ AMP. Additionally, supplementing AMP up to a level of 10 or $15 \mathrm{~g} / \mathrm{kg}$ of diet quadratically increased immunoglobulin and interleukin contents in the serum.

Conclusion: The results indicated that AMP can be used as natural feed additive in the ration of lambs to improve $\mathrm{ADG}$, antioxidant status, and immune functions, and the optimal dose was $10 \mathrm{~g} / \mathrm{kg}$ of diet under the condition of this experiment.

Keywords: Astragalus membranaceus Root; Growth Performance; Antioxidant Status; Immune Response; Lamb

\section{INTRODUCTION}

Over the past few decades, antibiotics have been used as animal growth promoters and antimicrobial drugs in livestock production. However, the use of antibiotics as growth promoters has been banned in many countries due to the great threat to food safety. Due to the high demand for organic animal products in the consumer market, attempts have been made to improve growth performance and immune function of finishing lambs by nutritional strategies instead of drugs enhancing performance. In recent years, different kinds of natural herbal plants, and/or their extracts, has been used as feed additives for animals due to their antimicrobial activities, immune enhancement and stress reduction 
properties [1,2].

The dried roots of Astragalus membranaceus (AM), also known as Huangqi, is a Chinese herbal medicine used in China for more than two thousand years, which contains more than 100 bioactive constituents, such as 24 polysaccharides, 11 monosaccharides, 13 triterpenes and flavonoids, 9 isoflavonoids, 25 amino acids, 21 inorganic elements, and $\gamma$-aminobutyric [3-6]. Previous studies have proved that AM roots possess growth-promoting, immunomodulatory, antioxidant, anti-bacterial, anti-viral and anti-inflammatory activities $[7,8]$. However, most of the research intensively focused on the physiological functions of AM or astragalus polysaccharide (APS) in humans and monogastric animals $[9,10]$. Available research data in terms of using AM to improve ruminant health are less common. Under intensive feeding conditions, the oxidative stress of fattening sheep increased. If $A M$ can improve the immune function and antioxidant function of fattening sheep, it will be of great significance to the sheepmeat industry.

The objective of this study was to determine effects of dietary AM roots supplementation on growth performance, serum metabolites, antioxidant status, and immune responses of finishing lambs.

\section{MATERIALS AND METHODS}

\section{Preparation and determination of the Astragalus membranaceus root powder}

The sun-dried roots of 3-year-old AM were purchased from Yingxian Qianbao Co. Ltd (Shanxi, China), dried at $65^{\circ} \mathrm{C}$ for
$3 \mathrm{~h}$ in electric thermostatic drying oven (Shantou Kehua Experimental equipment Co. Ltd., Shantou, China), and then ground to pass through a 2-mm screen to be an Astragalus membranaceus powder (AMP). The AMP was stored at ambient temperature $\left(21^{\circ} \mathrm{C}\right.$ to $\left.24^{\circ} \mathrm{C}\right)$ before being mixed into the diets. The total polysaccharides were measured according to description of Yang et al [11]. The astragalosides and flavonoids were determined by high performance liquid chromatography analysis according to the method of Peng et al [5]. The chemical composition of AMP was shown in Table 1.

\section{Animals, diets, and experimental design}

The use of the animals was approved by the Animal Care Committee, Shanxi Agricultural University (Taigu, China), and experimental procedures used in this study were in accordance with the university's guidelines for animal research.

The experiment was arranged as a complete randomized design. Thirty-six Guangling fat-tailed ram lambs with similar weights (body weight $[\mathrm{BW}]=19 \pm 2 \mathrm{~kg}$ ) were randomly divided into six groups and allocated to 1 of 6 treatments. The treatments were: basal diet (control) and basal diet supplemented with AMP at the levels of 5, 10, 15, 20, and $30 \mathrm{~g} / \mathrm{kg}$ of diet (treatments denoted as AMP5, AMP10, AMP15, and AMP20, and AMP30, respectively) by replacing equivalent amounts of corn straw in the diet formulation.

Diets were formulated to meet nutrient requirements of the animals [12]. Roughage and concentrate in diets were pelleted using a horizontal feed mixer (9SJW-300; National Science Makoto Farming Equipment Co. Ltd., Beijing, China), and the AMP was mixed during pelleting. The ration ingre-

Table 1. Ingredients and chemical compositions of experimental diets and active ingredients of Astragalus membranaceus

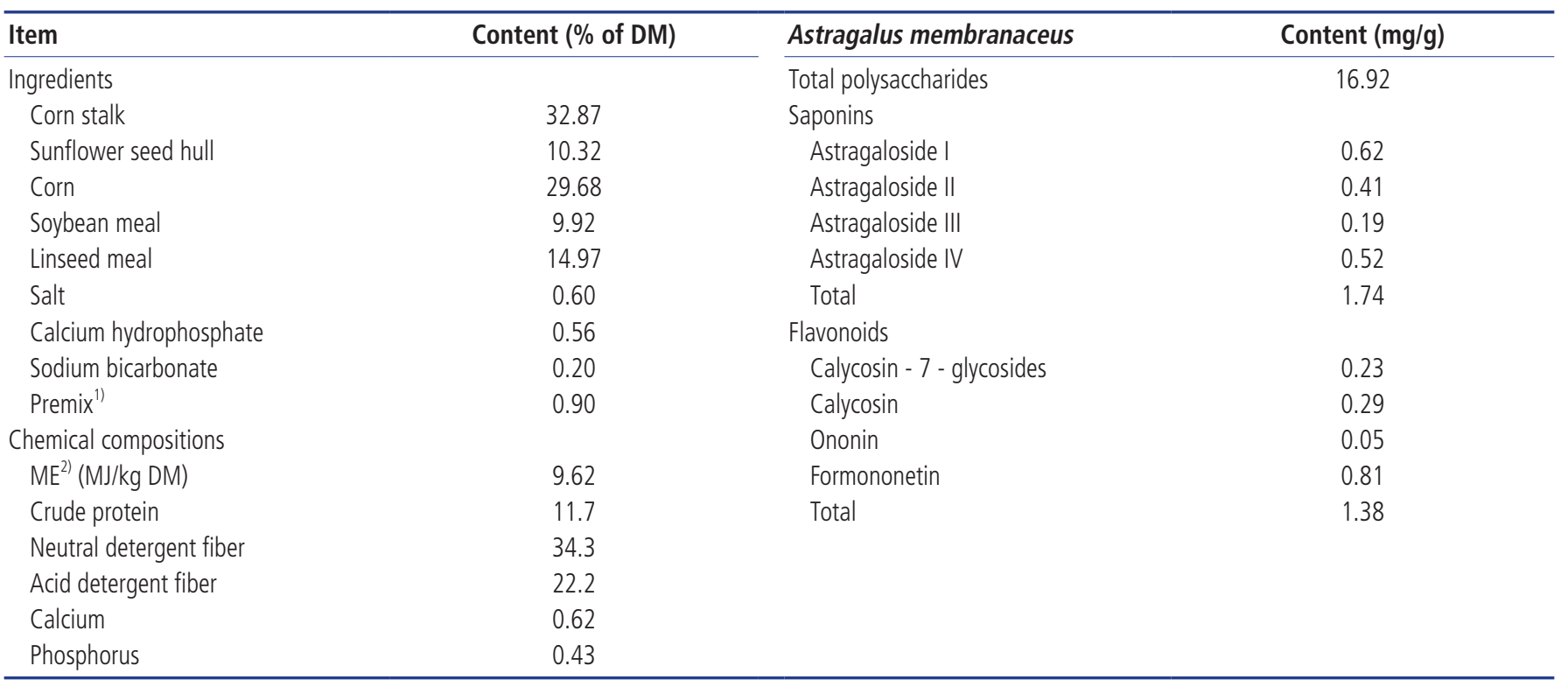

AM, Astragalus membranaceus; DM, dry matter; ME, metabolizable energy.

1) Premix containing: $40 \mathrm{mg} / \mathrm{kg}$ of Fe, $20 \mathrm{mg} / \mathrm{kg}$ of Mn, $40 \mathrm{mg} / \mathrm{kg}$ of Zn, $15 \mathrm{mg} / \mathrm{kg}$ of Cu, $0.2 \mathrm{mg} / \mathrm{kg}$ of I, $0.2 \mathrm{mg} / \mathrm{kg}$ of Co, $0.2 \mathrm{mg} / \mathrm{kg}$ of Se.

${ }^{2)} \mathrm{ME}$ was a calculated value, while the others were measured values. 
dient composition and nutrient levels were shown in Table 1. The experiment was conducted over $40 \mathrm{~d}$, with the first $10 \mathrm{~d}$ for adaptation. Lambs were housed in individual stalls (3.0 $\mathrm{m} \times 0.8 \mathrm{~m})$ and fed twice daily (07:00 and 17:00 h) at 105\% of ad libitum intake and had free access to drinking water.

\section{Sample collection and analysis}

During the experimental period, feed intake and refusal were recorded daily, and BW was weighed before the morning feeding for each lamb during a 3-d period at the start and end of experiment to determine dry matter intake (DMI), average daily gain (ADG), and feed conversion ratio. The contents of dry matter (DM) and crude protein, calcium, and phosphorus in diets were determined according to the method 930.15, 976.05, 927.02, 965.17 in official methods of analysis of the AOAC [13]. Neutral detergent fiber and acid detergent fiber content was analyzed using the Ankom A200 fiber analyzer (Ankom Technology, Macedon, NY, USA) by the method of Van Soest et al [14].

Blood samples were collected from the jugular vein using $10 \mathrm{~mL}$ evacuated blood-collection tubes before the morning feeding on the last day of the experiment period. Blood was centrifuged at 3,000 r/min for $15 \mathrm{~min}$ and serum was collected and stored at $-20^{\circ} \mathrm{C}$ before analysis for total antioxidant capacity (T-AOC), malondialdehyde (MDA), hydroxyl radical inhibition capability $\left(\mathrm{OH}^{-}\right)$, activities of glutathione peroxidase (GSH-Px), and total superoxide dismutase (T-SOD). These indicators were determined by colorimetry using standard commercial kits (Beijing Huaying Bioengineering Institute, Beijing, China) according to the manufacturer's instructions. The content of total protein, globulin (GLO), albumin (ALB), blood urea nitrogen (BUN), triglyceride (TG), total cholesterol (TC), high density lipoprotein cholesterol (HDLC), low density lipoprotein cholesterol (LDLC), glucose (GLU), creatinine (Cr), activity of alanine aminotransferase (ALT), aspartate aminotransferase (AST) and alkaline phosphatase were determined using a fully automatic biochemistry analyzer (Shenzhen Mindrary Bio-Medical
Electronics Co. Ltd. Shenzhen, China). The content of nitric oxide (NO) was determined by nitric reductase method using commercial kits (Shanghai Ruiqi Bioengineering Institute, Shanghai, China). The levels of immunoglobulin A (IgA), IgM, IgE, interleukin-2 (IL-2), IL-6, lysozyme (LZM), nitric oxide synthase (NOS), alexin $\mathrm{C} 3$ and $\mathrm{C} 4$, and tumor necrosis factor- $\alpha$ were determined by enzyme-linked immunosorbent assay commercial kits (Wuhan Boster Bioengineering Limited Company, Wuhan, China).

\section{Statistical analysis}

Data were analyzed statistically by one-way analysis of variance using the general linear model procedures of SAS (version 9.1, SAS Institute Inc., Cary, NC, USA), where dietary concentration of AMP as the treatment effect. Each sheep was defined as the experimental unit. In addition, the linear and quadratic effects of treatment were tested by an orthogonal polynomial contrast. Means were considered significantly different at $\mathrm{p}<0.05$, and tendencies for treatment effects were defined as $\mathrm{p}<0.10$.

\section{RESULTS}

\section{Feed intakes and lamb performances}

The DMI and growth performance are shown in Table 2. The initial BW of lambs was similar, but supplementation of AMP up to a level of $10 \mathrm{~g} / \mathrm{kg}$ of diet quadratically increased final weight. The DMI was not affected by treatment $(\mathrm{p}=0.227)$. The addition of AMP also displayed a quadratic response on the ADG $(p=0.032)$ and DMI/ADG ratio, with the greatest and lowest values for AMP10 diet $(261.0 \mathrm{~g} / \mathrm{d}$ and 3.98, respectively).

\section{Serum metabolites and indices of liver and renal function}

The increase of AMP supplementation in the ration resulted in a quadratic response in contents of TG and creatinine ( $\mathrm{p}<$ 0.05 ; Table 3), and the values of 10 to $20 \mathrm{~g} / \mathrm{kg}$ were lower. A

Table 2. Effects of Astragalus membranaceus roots on dry matter intake and growth performance of ram lambs

\begin{tabular}{|c|c|c|c|c|c|c|c|c|c|}
\hline \multirow{2}{*}{ Items } & \multicolumn{6}{|c|}{ Dietary treatment $^{1)}$} & \multirow{2}{*}{ SEM } & \multicolumn{2}{|c|}{ Contrast p-value } \\
\hline & Control & AMP5 & AMP10 & AMP15 & AMP20 & AMP30 & & Linear & Quadratic \\
\hline Initial weight (kg) & 19.5 & 19.5 & 19.5 & 20.4 & 19.8 & 19.5 & 0.56 & 0.175 & 0.258 \\
\hline$A D G(g / d)$ & $210.8^{a b}$ & $212.7^{a b}$ & $261.0^{\mathrm{a}}$ & $179.7^{b}$ & $181.4^{b}$ & $180.3^{b}$ & 25.34 & 0.560 & 0.032 \\
\hline DMI (g/d) & 957.0 & 922.8 & $1,021.9$ & 915.9 & 866.3 & 868.3 & 73.48 & 0.392 & 0.227 \\
\hline DMI/ADG & $4.60^{\mathrm{ab}}$ & $4.41^{\mathrm{ab}}$ & $3.98^{b}$ & $4.81^{\mathrm{a}}$ & $4.78^{\mathrm{a}}$ & $4.85^{\mathrm{a}}$ & 0.26 & 0.860 & 0.050 \\
\hline
\end{tabular}

AMP, Astragalus membranaceus root powder; SEM, standard error of the mean; ADG, average daily gain; DMI, dry matter intake.

1) Control, AMP5, AMP10, AMP15, AMP20, and AMP30 were ram lambs fed the basal diet and the basal diet supplemented with AMP at a concentration of 5, 10, 15, 20, or

$30 \mathrm{~g} / \mathrm{kg}$, respectively.

2) Dose response (linear or quadratic) to different levels of AMP supplementation.

${ }^{a b}$ Means within a row with different superscripts differ $(p<0.05)$. 
Table 3. Effects of the Astragalus membranaceus roots supplementation on serum biochemical index and enzymes related to liver function of ram lambs

\begin{tabular}{|c|c|c|c|c|c|c|c|c|c|}
\hline \multirow{2}{*}{ Items } & \multicolumn{6}{|c|}{ Dietary treatment $^{1)}$} & \multirow{2}{*}{ SEM } & \multicolumn{2}{|c|}{ Contrast $p$-value ${ }^{2)}$} \\
\hline & Control & AMP5 & AMP10 & AMP15 & AMP20 & AMP30 & & Linear & Quadratic \\
\hline Total protein (g/L) & 66.38 & 68.32 & 69.64 & 69.00 & 69.00 & 65.52 & 0.72 & 0.657 & 0.114 \\
\hline$A L B(g / L)$ & 28.24 & 28.04 & 29.06 & 28.36 & 28.03 & 28.92 & 0.25 & 0.591 & 0.846 \\
\hline GLO (g/L) & 38.14 & 40.28 & 40.58 & 40.64 & 40.96 & 36.50 & 0.69 & 0.510 & 0.069 \\
\hline BUN (mmoL/L) & 8.66 & 9.46 & 9.68 & 10.00 & 9.45 & 9.24 & 0.19 & 0.551 & 0.178 \\
\hline $\mathrm{TC}(\mathrm{mmol} / \mathrm{L})$ & 1.46 & 1.39 & 1.42 & 1.62 & 1.31 & 1.34 & 0.04 & 0.468 & 0.635 \\
\hline $\mathrm{TG}(\mathrm{mmol} / \mathrm{L})$ & $0.50^{\mathrm{a}}$ & $0.40^{\mathrm{ab}}$ & $0.35^{b}$ & $0.38^{\mathrm{ab}}$ & $0.32^{b}$ & $0.40^{\mathrm{ab}}$ & 0.01 & 0.149 & 0.023 \\
\hline HDLC (mg/dL) & 0.98 & 0.93 & 1.06 & 1.05 & 0.85 & 0.98 & 0.03 & 0.678 & 0.907 \\
\hline LDLC (mg/dL) & 0.47 & 0.44 & 0.44 & 0.53 & 0.42 & 0.42 & 0.02 & 0.563 & 0.695 \\
\hline GLU (mmol/L) & 2.49 & 1.91 & 1.83 & 2.09 & 1.88 & 1.91 & 0.08 & 0.09 & 0.063 \\
\hline $\mathrm{Cr}(\mu \mathrm{mol} / \mathrm{L})$ & $50.58^{b c}$ & $51.18^{b}$ & $49.10^{b c}$ & $45.23^{\mathrm{bc}}$ & $44.03^{c}$ & $57.63^{\mathrm{a}}$ & 1.12 & 0.097 & 0.012 \\
\hline ALT (IU/L) & 13.5 & 11.96 & 14.56 & 13.14 & 13.73 & 8.28 & 0.87 & 0.159 & 0.122 \\
\hline AST (IU/L) & 101.8 & 95.7 & 111.2 & 105.6 & 115.3 & 109.5 & 3.25 & 0.201 & 0.364 \\
\hline ALP (IU/L) & $407.3^{\mathrm{a}}$ & $390.6^{\mathrm{a}}$ & $409.5^{\mathrm{a}}$ & $344.5^{\mathrm{ab}}$ & $256.8^{b}$ & $247.7^{\mathrm{b}}$ & 18.28 & 0.0001 & 0.136 \\
\hline
\end{tabular}

AMP, Astragalus membranaceus root powder; SEM, standard error of the mean; ALB, albumin; GLO, globulin; BUN, urea nitrogen; TC, cholesterol; TG, triglyceride; HDLC, high density lipoprotein cholesterol; LDLC, low density lipoprotein cholesterol; GLU, glucose; Cr, creatinine; ALT, alanine aminotransferase; AST, aspartate aminotransferase; ALP, alkaline phosphatase.

1) Control, AMP5, AMP10, AMP15, AMP20, and AMP30 were ram lambs fed the basal diet and the basal diet supplemented with AMP at a concentration of 5, 10, 15, 20, or $30 \mathrm{~g} / \mathrm{kg}$, respectively.

${ }^{2)}$ Dose response (linear or quadratic) to different levels of AMP supplementation.

${ }^{a-c}$ Means within a row with different superscripts differ $(p<0.05)$.

linear decrease was observed in activity of ALP in serum of lambs $(\mathrm{p}=0.0001)$. Nearly quadratic effect in concentration of GLO and GLU were also observed ( $p=0.069$ and $p=$ 0.063). But the contents of total protein, ALB, TC, HDLC, LDLC, BUN, AST, and ALT in serum was not affected by AMP supplementation ( $p>0.05)$.

\section{Antioxidant function}

As shown in Table 4, no significant effect of AMP supplementation was detected on GSH-Px activity in serum ( $\mathrm{p}=$ 0.406). Supplementing AMP linearly promoted T-SOD activity $(\mathrm{p}=0.018)$ and linearly declined $\mathrm{OH}$ - concentration $(p=0.002)$. The MDA contents decreased as the AMP supplementation increased in the diet, and both the linear and quadratic effects were significant ( $\mathrm{p}=0.001)$, with lowest value for AMP10. Additionally, feeding of AMP displayed a quadratic $(p=0.040)$ response on the CAT activity, with the greatest value for AMP5 and AMP10. T-AOC was linearly (p $=0.043$ ) increased by the addition of AMP to the diet.

\section{Immune function}

The results of immune function are listed in Table 5. Supplementing AMP up to a level of 10 or $15 \mathrm{~g} / \mathrm{kg}$ of diet quadratically increased $\operatorname{IgA}(\mathrm{p}=0.037), \operatorname{IgM}(\mathrm{p}<0.0001)$, and $\operatorname{IgG}(\mathrm{p}=$ 0.0003 ) contents in the serum. There were also quadratic effects on IL-2 and IL-6, with the greatest values at AMP5 and AMP10. The concentrations of alexin C3 and C4, NO, LZM, and NOS activity were not affected ( $p>0.101)$ by the addition

Table 4. Effects of the Astragalus membranaceus roots supplementation on antioxidant function of ram lambs

\begin{tabular}{|c|c|c|c|c|c|c|c|c|c|}
\hline \multirow{2}{*}{ Items } & \multicolumn{6}{|c|}{ Dietary treatment $^{1)}$} & \multirow{2}{*}{ SEM } & \multicolumn{2}{|c|}{ Contrast $p$-value $^{2)}$} \\
\hline & Control & AMP5 & AMP10 & AMP15 & AMP20 & AMP30 & & Linear & Quadratic \\
\hline GSH-Px (IU/mL) & 807 & 849.1 & 845.5 & 842.5 & 800.7 & 792 & 27.15 & 0.406 & 0.425 \\
\hline T-SOD (IU/mL) & $70.0^{b}$ & $79.2^{b}$ & $83.8^{a b}$ & $81.0^{\mathrm{ab}}$ & $88.2^{a}$ & $77.2^{b}$ & 4.74 & 0.018 & 0.091 \\
\hline $\mathrm{OH}^{-}(\mathrm{IU} / \mathrm{mL})$ & $702.7^{a}$ & $686.0^{a b}$ & $648.6^{b c}$ & $646.2^{b c}$ & $620.6^{c}$ & $602.2^{c}$ & 25.73 & 0.002 & 0.765 \\
\hline CAT (IU/mL) & $46.0^{b}$ & $51.3^{\mathrm{a}}$ & $52.9^{\mathrm{a}}$ & $47.3^{a b}$ & $47.8^{\mathrm{ab}}$ & $47.6^{a b}$ & 2.14 & 0.869 & 0.040 \\
\hline MDA (nmol/mL) & $5.34^{\mathrm{a}}$ & $4.09^{b}$ & $3.18^{c}$ & $3.45^{b}$ & $4.07^{b}$ & $4.33^{b}$ & 0.378 & 0.001 & 0.001 \\
\hline T-AOC (IU/mL) & $5.95^{b}$ & $6.42^{\mathrm{ab}}$ & $6.36^{\mathrm{ab}}$ & $6.48^{\mathrm{ab}}$ & $6.97^{\mathrm{a}}$ & $7.33^{\mathrm{a}}$ & 0.458 & 0.043 & 0.481 \\
\hline
\end{tabular}

AMP, Astragalus membranaceus root powder; SEM, standard error of the mean; GSH-Px, glutathione peroxidase; T-SOD, total superoxide dismutase; OH', hydroxyl radical inhibition capability; CAT, catalase; MDA, malondialdehyde; T-AOC, total antioxidant capacity.

1) Control, AMP5, AMP10, AMP15, AMP20, and AMP30 were ram lambs fed the basal diet and the basal diet supplemented with AMP at a concentration of 5, 10, 15, 20, or $30 \mathrm{~g} / \mathrm{kg}$, respectively.

2) Dose response (linear or quadratic) to different levels of AMP supplementation.

a-c Means within a row with different superscripts differ $(p<0.05)$. 
Table 5. Effects of the Astragalus membranaceus roots on immune function of ram lambs

\begin{tabular}{|c|c|c|c|c|c|c|c|c|c|}
\hline \multirow{2}{*}{ Items } & \multicolumn{6}{|c|}{ Dietary treatment $^{1)}$} & \multirow{2}{*}{ SEM } & \multicolumn{2}{|c|}{ Contrast $p$-value ${ }^{2)}$} \\
\hline & Control & AMP5 & AMP10 & AMP15 & AMP20 & AMP30 & & Linear & Quadratic \\
\hline $\lg A(g / L)$ & $0.46^{b}$ & $0.49^{b}$ & $0.51^{b}$ & $0.60^{a}$ & $0.48^{b}$ & $0.50^{b}$ & 0.012 & 0.102 & 0.037 \\
\hline $\operatorname{lgM}(\mathrm{g} / \mathrm{L})$ & $1.05^{b}$ & $1.19^{b}$ & $1.52^{\mathrm{a}}$ & $1.53^{\mathrm{a}}$ & $1.11^{b}$ & $1.22^{b}$ & 0.040 & 0.399 & $<0.0001$ \\
\hline $\lg G(g / L)$ & $20.5^{b}$ & $22.6^{b}$ & $28.2^{\mathrm{a}}$ & $29.0^{\mathrm{a}}$ & $19.6^{b}$ & $21.5^{b}$ & 0.95 & 0.239 & 0.0003 \\
\hline $\operatorname{lgE}(I U / m L)$ & 43.0 & 42.4 & 44.2 & 45.6 & 43.5 & 42.7 & 0.61 & 0.183 & 0.536 \\
\hline TNF (pg/mL) & 63.5 & 62.0 & 61.8 & 63.3 & 62.4 & 61.7 & 0.87 & 0.929 & 0.523 \\
\hline IL-2 (ng/mL) & $3.74^{b}$ & $6.26^{\mathrm{a}}$ & $6.96^{\mathrm{a}}$ & $3.13^{b}$ & $3.29^{b}$ & $2.39^{b}$ & 0.322 & 0.522 & $<0.0001$ \\
\hline IL-6 (pg/mL) & $106.9^{b}$ & $122.5^{\mathrm{ab}}$ & $128.5^{\mathrm{a}}$ & $113.9^{\mathrm{ab}}$ & $112.8^{\mathrm{ab}}$ & $105.4^{b}$ & 2.83 & 0.360 & 0.031 \\
\hline Alexin C3 (g/L) & 0.48 & 0.43 & 0.38 & 0.47 & 0.42 & 0.40 & 0.021 & 0.717 & 0.146 \\
\hline Alexin C4 (g/L) & 0.098 & 0.089 & 0.077 & 0.088 & 0.081 & 0.074 & 0.006 & 0.367 & 0.354 \\
\hline $\mathrm{NO}(\mu \mathrm{mol} / \mathrm{L})$ & 34.3 & 32.3 & 33.6 & 35.8 & 35.5 & 34.5 & 0.59 & 0.287 & 0.101 \\
\hline NOS (U/mL) & 19.3 & 18.7 & 18.9 & 18.9 & 20.4 & 18.0 & 0.66 & 0.834 & 0.820 \\
\hline LZM ( $\mu \mathrm{g} / \mathrm{mL})$ & 21.0 & 22.6 & 22.1 & 23.1 & 22.4 & 20.6 & 0.37 & 0.309 & 0.401 \\
\hline
\end{tabular}

AMP, Astragalus membranaceus root powder; SEM, standard error of the mean; Ig, immunoglobulin; TNF- $\alpha$, tumor necrosis factor- $\alpha$; IL, interleukin; NO, nitric oxide; NOS, nitric oxide synthase; LZM, lysozyme.

1) Control, AMP5, AMP10, AMP15, AMP20, and AMP30 were ram lambs fed the basal diet and the basal diet supplemented with AMP at a concentration of 5, 10, 15, 20, or $30 \mathrm{~g} / \mathrm{kg}$, respectively.

2) Dose response (linear or quadratic) to different levels of AMP supplementation.

${ }^{a b}$ Means within a row with different superscripts differ $(p<0.05)$.

of AMP to the diet.

\section{DISCUSSION}

The AM is a type of traditional Chinese herbal medicine, which grows wildly or semi-wildly in Yingxian and Hunyuan county, Shanxi province, China. It has been reported that AM root produced in Shanxi has a good quality, which contains $1.49 \mathrm{~g} / \mathrm{kg}$ total isoflavonoids, $2.12 \mathrm{~g} / \mathrm{kg}$ total astragaloside, $13.48 \mathrm{~g} / \mathrm{kg}$ total polysaccharides, $30.3 \mathrm{~g} / \mathrm{kg}$ total amino acids, $0.57 \mathrm{~g} / \mathrm{kg} \gamma$-aminobutyric acid [3]. Bioactive ingredients especially are rich in 3-year-old AM root. The AMP used in our study contained total polysaccharides $16.92 \mathrm{mg} / \mathrm{g}$ AMP, astragalosidesI-IV $1.74 \mathrm{mg} / \mathrm{g}$ AMP, four flavonoids $1.38 \mathrm{mg} / \mathrm{g}$ (Table 1), which have many biological activities, such as a growth-promoting function, immunomodulatory activity, antioxidant activity, and so on [15].

In recent years, there have been many successful applications of AMP in mono-gastric animals. Some researchers have shown that AMP supplementation accelerates weight gain in broilers [9], increases the laying rate and egg mass and improves the quality of laying hen [10]. However, limited studies to date have examined effects of feeding AMP on DM intake and growth performance in ruminants. In the present study, the growth performance data showed that all dietary treatments did not affect DMI and only AMP supplemented at the level of $10 \mathrm{~g} / \mathrm{kg}$ increased ADG of lambs. Likewise, the improvement in feed conversion was mainly due to the increased ADG rather than the effect on feed intake. This indicates that AMP supplemented at the level of $10 \mathrm{~g} / \mathrm{kg}$ diet has growth-promoting effect on finishing lambs. How- ever, the growth-promoting effect of AMP on finishing lambs was not linear. This illustrated that AMP can promote growth of lambs at appropriate level, and that more is not better. This may be due to the adverse effects of high doses of AMP on rumen microorganisms, which need further study. In contrast to our results, Zhong et al [2] reported that AM root supplementation had no effects on feed intake, ADG, feed efficiency and apparent digestibility of nutrients. Differences may be due to the higher dose level $(50 \mathrm{~g} / \mathrm{d})$ of AMP in their study. Because our results also showed a quadratic effect on growth performance, and high dose AMP did not increase ADG. Zhong et al [2] also reported that AM root supplementation increased the concentration of volatile fatty acids and ammonia nitrogen in the rumen, which provided more energy and nitrogen sources for animals and rumen microorganisms, and ultimately was conducive to the growth of lambs. Additionally, previous studies have reported that Astragalus root contains varieties of chemical compounds which have varying pharmaceutical and biological activities, such as antioxidant, antimicrobial, and immune-enhancing functions $[3,16]$. However, some components such as saponin and polyphenolics may have anti-nutritional effects $[17,18]$. Therefore, adding high AMP to the diet may have negative effects on nutrients digestion and absorption. Besides, as a kind of herbal medicine, AM may not be added to animal diets for too long. In most studies on the application effect of Chinese herbal medicine in animal production, the experimental period was usually set at 30 to 40 days $[2,19,20]$. In present study, we determined the growth performance of lambs added AMP for 40 days. Moreover, it is necessary to further study whether the long-term addition of AMP has 
negative effects on animals.

Prior works have documented that polysaccharides and flavonoid glycosides extracted from AM root plays an essential role in regulation of glucose and lipid metabolism $[6,21]$. In our study serum TG and GLU content quadratically decreased with the increase of the AMP supplementation, which is consistent with those of Zou et al [22] and Chen et al [23], finding that administration of polysaccharides of AM could improve glucose uptake in rats and decrease the blood TG and promote the lipid metabolism in diabetic hamster.

Elevation of serum ALT, AST, and ALP activity indicates the abnormality of liver function [24]. And the increase of creatinine concentration in serum results in renal injury [25]. The linear and quadratic decrease of ALP and the quadratic reduction of creatinine suggested that the addition of AMP in the ration of finishing lambs improved the liver function and renal function in this study. This is in line with the observation of Zhang et al [26], who found that the polysaccharides of AM improved the renal function in diabetic rats. When the cells receive stimuli, such as oxidative stress, nuclear factor$\kappa \mathrm{B}$ is released from inhibitory protein compound (I $\mathrm{B}$ ) to activate the gene expression of inflammatory cytokines and proliferation, which might contribute to the liver and renal damage. Nevertheless, APS could improve kidney function by reducing the mRNA level of nuclear factor- $\mathrm{kB}$ and raising the IкB mRNA expression [26]. Sun et al [27] also found the hepato-protective activity of AM might be associated its ability of scavenge free radicals and antioxidant. However, when the supplementation level of AMP was up to $30 \mathrm{~g} / \mathrm{kg}$ for $30 \mathrm{~d}$, serum creatinine concentration rose again in our study, which inferred that $30 \mathrm{~g} / \mathrm{kg}$ supplementation of AMP in the long term may have an adverse effect on kidney.

The increased activities of T-SOD, CAT, and T-AOC but reduced $\mathrm{OH}^{-}$and MDA concentration in the serum with AMP supplementation in this study indicated that AMP enhanced the antioxidant status of finishing lamb. This is consistent with the observation of Zhong et al [2], who also reported that increased activities of T-AOC, T-SOD, and CAT in the serum of weaned lambs resulted from dietary AMP supplementation at levels of $50 \mathrm{~g} / \mathrm{kg}$. It is well known that GSH-Px, T-SOD, and CAT are endogenous antioxidant enzymes which constitute the antioxidant defense enzymatic system. Therefore, the higher activities of these enzymes in the AMP-treatments in this study may have resulted in a greater capacity of lambs to scavenge free radicals and reactive oxygen species and reduce the MDA concentration, as indicated by the lower extent of lipid peroxidation. Additionally, the linearly increase of serum antioxidant status with AMP supplementation was due to the combined effect of antioxidant compounds in AMP. It is reported that there are varieties of naturally biological compounds (such as polysaccharides, saponins, and flavonoids, etc.) in AM, which have strong antioxidant activities [28,29]. These exogenous antioxidants can improve the antioxidant status by increasing endogenous antioxidants and scavenging free radical to some extent $[27,30]$. Our results show that supplement AMP exhibited antioxidant effects in finishing lambs, indicated that AMP might help alleviate the oxidative stress of lambs during high density finishing period in production.

As we all know, the immune state of the body is influenced by the degree of oxidative stress and the intake of antioxidants [31]. Exogenous antioxidants can alleviate oxidative stress by reducing lipid peroxidation and scavenging free radicals, and ultimately play an immunopotentiating role. Previous studies reported that polysaccharide fractions in AMP have extensive effects on alleviating immune stress and activating the immune system [20,32]. Astragalus polysaccharide can modulate humoral and cellular immune response, including increasing the production of antigen-specific antibody, activating $B$ cells and macrophages, promoting $T$ cell proliferation and regulating cytokine productions $[33,34]$. In our study, AMP supplemented at the level of 10 and $15 \mathrm{~g} / \mathrm{kg}$ diet did affect immune responses of lambs, including inducing IgA, IgG, and IgM productions, and when the AMP supplemented at the level of 5 and $10 \mathrm{~g} / \mathrm{kg}$ diet, the concentrations of IL-2 and IL- 6 in serum were increased. These responses may protect lambs against pathogenic and nonpathogenic immune challenges. Therefore, we suspect that the immunomodulatory effect of AMP is partly due to the polysaccharide fractions (169.2 mg/10 g AMP, Table 1) in present study. However, Zhong et al [2] showed that supplementation with astragalus polysaccharide at $15 \mathrm{~g} / \mathrm{kg}$ diet did not affect the immune responses of lambs and the possible reason may be that the supplemented dose was suboptimal. Additionally, Mao et al [20] found that saponin and beta-glucan in AMP have strong immune-enhancing effects in weaned pigs. In other words, there are many bioactive ingredients in AMP which have potent immune modulation properties. Therefore, future studies need to determine the mechanism of functional constituents in regulating immune function for lambs.

\section{CONCLUSION}

Results from this study show that supplementing the diets of finishing lambs with AMP at the level of $10 \mathrm{~g} / \mathrm{kg}$ increased growth performance without affecting DMI. Supplementation of AMP enhanced antioxidant status and retarded lipid oxidation in the serum. Additionally, AMP possessed immunomodulating effect at 10 and $15 \mathrm{~g} / \mathrm{kg}$ diet by improving serum immunoglobulin and interleukin. However, when the dosage exceeded $20 \mathrm{~g} / \mathrm{kg}$, the effect was not significant. Consequently, we infer that AMP can be used as a natural feed additive in the finishing lambs, and the optimal dose was 10 $\mathrm{g} / \mathrm{kg}$ under the condition of this study. 


\section{IMPLICATIONS}

Astragalus membranaceus root, a well-known Chinese herbal medicine, is used as a potential antioxidant and immunomodulating agent in Chinese medicinal prescriptions. Supplementing Astragalus membranaceus root up to a level of $10 \mathrm{~g} / \mathrm{kg}$ of diet promotes the growth performance, and improves antioxidant status and immune functions in finishing lambs. However, when the dosage exceeded $20 \mathrm{~g} / \mathrm{kg}$, the effect was not obvious. Therefore, Astragalus membranaceus root will be as a safe feed additive in the ration of finishing lambs in sheep production.

\section{CONFLICT OF INTEREST}

We certify that there is no conflict of interest with any financial organization regarding the material discussed in the manuscript.

\section{ACKNOWLEDGMENTS}

This study was financially supported by China Agriculture Research System (CARS-38), “1331 Project” Key Disciplines of Animal Sciences, Shanxi Province (J201911301), Basic Research Project, Shanxi Province (201801D221291), and Shanxi Province Outstanding Doctor Award Fund (SXYBKY 201707). The authors also appreciate Institution of husbandry and veterinary in Yingxian for providing Astragalus membranaceus root and the experimental field. We would like to extend our most sincere appreciation to the College of Animal Science and Veterinary Medicine, Shanxi Agricultural University. Also, we thank Ng Ee Ling (university of Melbourne, Australia) for editing the final English version of this manuscript and polishing the English language.

\section{REFERENCES}

1. Ding YY, Zhang CH, He XL, Huang L, Yin ZJ. Growth performance responses and indicators of gastrointestinal health in early weaned pigs fed Chinese herbal medicine additivessupplemented diets. J Anim Vet Adv 2011;12:1580-7. https:// doi.org/10.3923/javaa.2011.1580.1587

2. Zhong RZ, Yu M, Liu HW, Sun HX, Cao Y, Zhou DW. Effects of dietary Astragalus polysaccharide and Astragalus membranaceus root supplementation on growth performance, rumen fermentation, immune responses, and antioxidant status of lambs. Anim Feed Sci Technol 2012;174:60-7. https://doi.org/ 10.1016/j.anifeedsci.2012.02.013

3. Ma XQ, Shi Q, Duan JA, Dong TTX, Tsim KWK. Chemical analysis of Radix Astragali (Huangqi) in China: a comparison with its adulterants and seasonal variations. J Agric Food Chem 2002;50:4861-6. https://doi.org/10.1021/jf0202279
4. Li L, Zheng S, Yang Q, Chen S, Huang L. Distinguishing Astragalus mongholicus and its planting soil samples from different regions by ICP-AES. Molecules 2016;21:482. https:// doi.org/10.3390/molecules21040482

5. Peng HS, Wang J, Zhang HT, et al. Rapid identification of growth years and profiling of bioactive ingredients in Astragalus membranaceus var. mongholicus (Huangqi) roots from Hunyuan, Shanxi. Chin Med 2017;12:14. https:/doi.org/10.1186/ s13020-017-0135-z

6. Liu W, Gao FF, Li Q, et al. Protective effect of Astragalus polysaccharides on liver injury induced by several different chemotherapeutics in mice. Asian Pac J Cancer Prev 2014; 15: 10413-20. https://doi.org/10.7314/ APJCP.2014.15.23.10413

7. Nie X, Shi B, Ao Z, Yin G, Tao W. Extraction of the Astragalus polysaccharides and its effects on the lymphocytes proliferation. J Anhui Agric Univ 2004;31:34-6.

8. Rui L, Chen WC, Wang WP, Tian WY, Zhang XG. Antioxidant activity of Astragalus polysaccharides and antitumour activity of the polysaccharides and siRNA. Carbohydr Polym 2010;82:240-4. https://doi.org/10.1016/j.carbpol.2010.02.048

9. Wang HF, Yang WR, Yang HW, et al. Effects of Astragalus membranaceus on growth performance, carcass characteristics, and antioxidant status of broiler chickens. Acta Agric Scand 2010;60:151-8. https://doi.org/10.1080/09064702.2010. 511255

10.Zuo ZY, Yang WR, Wang Y, Yang ZB, Jiang SZ, Zhang GG. Effects of Astragalus membranaceus on laying performance and antioxidant status of laying hens. J Appl Poult Res 2012; 21:243-50. https://doi.org/10.3382/japr.2011-00351

11. Yang L, Wang ZH, Tao JS. Comparison of the methods for determination of Astraglus polysaccharides in radix Astragali. Chin J Pharm 2005;36:562-3. https://doi.org/10.3969/j.issn. 1001-8255.2005.09.019

12. Nutrient requirements of small ruminants, sheep, goats, cervids and New World Camelids. Washington, DC, USA: National Academy Press; 2007.

13. Association of Official Analytical Chemists (AOAC). Official Methods of Analysis. 15th ed. Arlington, VA, USA: Association of Official Analytical Chemists; 1990.

14. Van Soest PJ, Robertson JB, Lewis BA. Methods for dietary fiber, neutral detergent fiber, and nonstarch polysaccharides in relation to animal nutrition. J Dairy Sci 1991;74:3583-97. https://doi.org/10.3168/jds.S0022-0302(91)78551-2

15. Jin M, Zhao K, Huang Q, Peng S. Structural features and biological activities of the polysaccharides from Astragalus membranaceus. Int J Biol Macromol 2014;64:257-66. https://doi. org/10.1016/j.ijbiomac.2013.12.002

16. Chen RZ, Tan L, Jin CG, et al. Extraction, isolation, characterization and antioxidant activity of polysaccharides from Astragalus membranaceus. Ind Crops Prod 2015;77:434-43. https:// doi.org/10.1016/j.indcrop. 2015.08.006

17. Jenkins KJ, Atwal AS. Effects of dietary saponins on fecal bile 
acids and neutral sterols, and availability of vitamins A and E in the chick. J Nutr Biochem 1994;5:134-7. https://doi.org/ 10.1016/0955-2863(94)90084-1

18.Gee JM, Wal JM, Miller K, et al. Effect of saponin on the transmucosal passage of $\beta$-lactoglobulin across the proximal small intestine of normal and $\beta$-lactoglobulin-sensitised rats. Toxicology 1997;117:219-28. https://doi.org/10.1016/S0300483X(96)03574-3

19.Zhang GG, Yang ZB, Wang Y, Yang WR. Effects of Astragalus membranaceus root processed to different particle sizes on growth performance, antioxidant status, and serum metabolites of broiler chickens. Poult Sci 2013;92:178-83. https://doi.org/ $10.3382 / \mathrm{ps} .2012-02432$

20. Mao XF, Piao XS, Lai CH, Li DF, Xing JJ, Shi BL. Effects of beta-glucan obtained from the Chinese herb Astragalus membranaceus and lipopolysaccharide challenge on performance, immunological, adrenal, and somatotropic responses of weanling pigs. J Anim Sci 2005;83:2775-82. https://doi.org/10.2527/ 2005.83122775x

21.Janibekova AA, Youssefb FS, Ashourb ML, Mamadalievaa NZ. New flavonoid glycosides from two Astragalus species (Fabaceae) and validation of their antihyperglycaemic activity using molecular modelling and in vitro studies. Ind Crops Prod 2018;118:142-8. https://doi.org/10.1016/j.indcrop.2018. 03.034

22.Zou F, Mao XQ, Wang N, Liu J, Ou-Yang JP. Astragalus polysaccharides alleviates glucose toxicity and restores glucose homeostasis in diabetic states via activation of AMPK. Acta Pharmacol Sin 2009;30:1607-15. https://doi.org/10.1038/aps. 2009.168

23. Chen W, Li YM, Yu MH. Astragalus polysaccharides inhibited diabetic cardiomyopathy in hamsters depending on suppression of heart chymase activation. J Diabetes Complications 2010;24:199-208. https://doi.org/10.1016/j.jdiacomp.2008. 12.003

24. Anoopraj R, Hemalatha S, Balachandran C. A preliminary study on serum liver function indices of diethylnitrosamine induced hepatocarcinogenesis and chemoprotective potential of Eclipta alba in male Wistar rats. Vet World 2014;7:439-42. https://doi.org/10.14202/vetworld.2014.439-442

25. Waikar SS, Betensky RA, Bonventre JV. Creatinine as the gold standard for kidney injury biomarker studies? Nephrol Dial
Transplant 2009;24:3263-5. https://doi.org/10.1093/ndt/gfp428

26.Zhang YW, Wu CY, Cheng JT. Merit of Astragalus polysaccharide in the improvement of early diabetic nephropathy with an effect on mRNA expressions of NF- $\kappa B$ and I $\kappa B$ in renal cortex of streptozotoxin-induced diabetic rats. J Ethnopharmacol 2007;114:387-92. https://doi.org/10.1016/j.jep.2007. 08.024

27.Sun WY, Wei W, Wu L, Gui SY, Wang H. Effects and mechanisms of extract from Paeonia lactiflora and Astragalus membranaceus on liver fibrosis induced by carbon tetrachloride in rats. J Ethnopharmacol 2007;112:514-23. https://doi.org/ 10.1016/j.jep.2007.04.005

28. Ma X, Tu P, Chen Y, Zhang T, Wei Y, Ito Y. Preparative isolation and purification of two isoflavones from Astragalus membranaceus Bge. var. mongholicus (Bge.) Hsiao by high-speed counter-current chromatography. J Chromatogr A 2003;992: 193-7. https://doi.org/10.1016/S0021-9673(03)00315-7

29. Kim JS, Yean MH, Lee EJ, et al. Two new cycloartane saponins from the roots of Astragalus membranaceus. Chem Pharm Bull 2008;56:105-8. https://doi.org/10.1248/cpb.56.105

30. Yan H, Xie YP, Sun SG, et al. Chemical analysis of Astragalus mongholicus polysaccharides and antioxidant activity of the polysaccharides. Carbohydr Polym 2010;82:636-40. https:// doi.org/10.1016/j.carbpol.2010.05.026

31. Miyazaki Y, Yamasaki M, Mishima H, Mansho K, Tachibana $\mathrm{H}$, Yamada K. Oxidative stress by visible light irradiation suppresses immunoglobulin production in mouse spleen lymphocytes. Biosci Biotechnol Biochem 2001;65:593-8. https://doi.org/10.1271/bbb.65.593

32.Jiang J, Wu C, Gao H, Song J, Li H. Effects of astragalus polysaccharides on immunologic function of erythrocyte in chickens infected with infectious bursa disease virus. Vaccine 2010;28:5614-6. https://doi.org/10.1016/j.vaccine.2010.06. 025

33. Shao P, Zhao LH, Chen Z, Pan JP. Regulation on maturation and function of dendritic cells by Astragalus mongholicus polysaccharides. Int Immunopharmacol 2006;6:1161-6. https://doi.org/10.1016/j.intimp.2006.02.009

34. Qin Q, Niu J, Wang Z, Xu W, Qiao Z, Gu Y. Astragalus embranaceus extract activates immune response in macrophages via heparanase. Molecules 2012;17:7232-40. https://doi.org/ 10.3390/molecules 17067232 